\title{
Idiopathic orthostatic hypotension from failure of noradrenaline release in a patient with vasomotor innervation
}

\author{
R. N. NANDA, ${ }^{1}$ F. C. BOYLE, J. S. GILLESPIE, R. H. JOHNSON, ${ }^{2}$ AND \\ H. J. KEOGH
}

From the University Department of Neurology, Institute of Neurological Sciences, Southern General Hospital, Glasgow, and the University Department of Pharmacology, Glasgow

SUMMARY A 26 year old man is described with life-long orthostatic hypotension unrelated to autonomic nerve degeneration and apparently due to failure of peripheral noradrenaline release. Tests of parasympathetic and sympathetic cholinergic nerve function were normal, but sympathetic adrenergic activity was defective. Thus blood pressure regulation was abnormal. There was no pressor response to tyramine, an indirect sympathomimetic drug, but a marked pressor response to the directly acting sympathomimetic drugs phenylephrine and noradrenaline. On standing there was a progressive fall rather than a rise in circulating noradrenaline concentrations, although adrenaline levels rose normally. The pupils showed diminished responses to ephedrine and cocaine, and a normal response to phenylephrine. Fluorescence microscopy of blood vessels showed that they were innervated with adrenergic nerves. His orthostatic hypotension responded well to oral phenylephrine ( $50 \mathrm{mg}$ five times daily) but not to other forms of therapy. It is suggested that this patient's symptoms were due to failure of noradrenaline release even though sympathetic adrenergic nerves were present. We therefore wish to draw attention to a further cause of orthostatic hypotension, failure of peripheral noradrenaline release without autonomic neuropathy.

Orthostatic hypotension may occur either as an idiopathic disorder or as a complication of many neurological disorders (Johnson and Spalding, 1974, 1976). The lesion may be in the afferent or efferent pathways, or in the central nervous system connections of the baroreceptor reflex arc controlling vasoconstriction. Reduced noradrenaline excretion has been reported in patients with idiopathic orthostatic hypotension (Luft and von Euler, 1953; Barnett et al., 1955; Hickler et al., 1959), and some of these patients lack the fluorescent fibres characteristic of sympathetic vasomotor innervation (Kontos et al., 1975). We now report a patient with idiopathic orthostatic hypotension who also had failure of peripheral noradrenaline release, but biopsy studies demonstrated that he had adrenergic innervation of blood vessels.

\footnotetext{
${ }^{1}$ Address for correspondence: Dr R. N. Nanda, Department of Medicine, Clinical Medical School, Wellington Hospital, Wellington 2, New Zealand.

${ }^{2}$ Present address as in ${ }^{1}$.

Accepted 30 August 1976
}

\section{Case report}

CLINICAL HISTORY

The patient (A. M., Institute of Neurological Sciences, Glasgow, 816955) complained of 'blackouts' from early childhood, at least since the age of 5 years. During the blackouts, which always occurred when standing, he had greying of vision, and would then frequently collapse unconscious for a few seconds. $\mathrm{He}$ had been unable to participate in games involving standing and running. He found that if he stood in a stooped manner, crossed his legs, or leant against a wall, symptoms were less frequent, and he adopted this posture as a habit. He attended school until the age of 15 years, and had earned his living as a bar tender. He had been married for two years and complained of impotence which had resulted in serious marital strife. He had normal penile erection, but there was no ejaculation. His past medical history was non-contributory, he was an only child, and his parents were alive and well. The parents' marriage was not consanguineous. He smoked over 20 cigarettes daily and drank alcohol in moderation. 
On examination he was thin, with an asthenic build, and pale but not obviously anaemic. He had a marked kyphosis. His height was $171.5 \mathrm{~cm}$ and his weight was $59 \mathrm{~kg}$. Blood pressure when lying was $127 / 70 \mathrm{mmHg}$, with pulse rate of 64 beats/min; on standing the blood pressure became unrecordable within one minute. Neurological examination, including tendon reflexes, was normal. External genitalia and secondary sexual characteristics were also normal.

\section{INVESTIGATIONS}

The following investigations were normal: ESR, haemoglobin, differential white cell count, blood urea and electrolytes (sodium, potassium, chloride, calcium and phosphate), alkaline phosphatase, bilirubin and flocculation tests, $\mathbf{B}_{12}$, Wassermann reaction, glucose tolerance test, urine excretion of 17-ketosteroids $(68.4 \mu \mathrm{mol} / 24 \mathrm{~h})$ and 17-hydroxycorticosteroids $(55.9 \mu \mathrm{mol} / 24 \mathrm{~h})$, urinary excretion of porphyrins (nil). Cerebrospinal fluid had normal findings for protein, cells and glucose. Urinary metadrenaline output was normal $(2.2 \mu \mathrm{mol} / 24 \mathrm{~h})$, and urinary vanillylmandelic acid output was low (6.6 $\mu \mathrm{mol} / 24 \mathrm{~h}$, normal range 10-35 $\mu \mathrm{mol} / 24 \mathrm{~h}$ ).

\section{AUTONOMIC FUNCTION \\ Change of posture}

On the morning of the investigation of arterial blood pressure responses, the patient stayed in bed and was taken to the laboratory and then transferred onto a tilt table. The arterial blood pressure was recorded with a catheter in the brachial artery. The catheter was connected to a strain gauge manometer recording system (Elema-Schönander) with the manometer fixed at the mid-sternal level. Its calibration was checked before and at the end of each investigation and when the patient's posture was changed. Heart rate was recorded continuously during the investigation with an electrocardiograph. Intravenous infusions were administered from a motor driven syringe through a 22 gauge cannula inserted under local anaesthesia into an antecubital vein in the opposite arm to that into which the blood pressure catheter had been inserted. Blood pressure and heart rate were observed while the patient's posture was changed and other tests were performed.

The patient was moved from the supine to the erect position. The blood pressure when he was supine was $110 / 70 \mathrm{mmHg}$, and it fell when he was in the erect position $\left(85^{\circ}\right)$ to $65 / 45 \mathrm{mmHg}$ within one minute. The heart rate was 64 beats/min in the supine position and increased to 98 beats/min one minute later. The patient complained of feeling faint and was returned to the horizontal position. The systolic and diastolic pressures rose again, but did not exceed the original resting levels. The procedure was repeated on three occasions within half an hour (Fig. 1). Arterial blood was sampled at the end of each tilt for estimation of circulating adrenaline and noradrenaline concentrations (Valori et al., 1970; Rennie, 1974). The resting levels of noradrenaline and adrenaline were $2.2 \mathrm{nmol} / 1$ and $0.25 \mathrm{nmol} / 1$ respectively. During the investigation, adrenaline levels rose to a maximum of $1.1 \mathrm{nmol} / \mathrm{l}$. The noradrenaline levels, however, fell, instead of rising, so that during the final tilt there was no measurable noradrenaline in the circulating blood.

\section{Valsalva's manoeuvre}

After a deep inspiration, the patient attempted a forced expiration for 10 seconds through a face mask connected by a thick-walled rubber tube to a strain gauge manometer and anaeroid manometer which the patient observed. The strain gauge manometer was attached to a chart recorder (Elema Schönander Mingograph). The patient was asked to maintain a pressure of $30-40 \mathrm{mmHg}$ for the $10 \mathrm{~s}$ period. The blood pressure fell progressively during the manoeuvre and a tachycardia developed (67 beats/min to 83 beats/min) but there was no overshoot of blood pressure after intrathoracic pressure returned to normal (a 'blocked response', Johnson and Spalding, 1974). As the blood pressure returned to normal, the heart rate was reduced to the original level.

\section{Heart rate changes with drugs and respiration}

Intravenous atropine sulphate $(3 \mathrm{mg})$ increased the patient's heart rate from resting values in the range of $53-60$ to $98-102$ beats $/ \mathrm{min}$. No further increase in heart rate could be obtained when orthostatic hypotension was induced by tilting. After the administration of atropine, propranolol $(0.2 \mathrm{mg} / \mathrm{kg}$ body weight $)$ produced no further significant change in heart rate (even in the presence of orthostatic hypotension produced by tilting). During deep breathing, the patient showed normal sinus arrhythmia which was abolished by atropine (Wheeler and Watkins, 1973).

\section{Sudden noise and mental arithmetic}

A starting pistol was fired immediately behind the patient without causing a rise in blood pressure. A simple standard test of addition and subtraction failed to produce a rise of blood pressure. Both these tests usually cause a rise of blood pressure in normal subjects (Johnson and Spalding, 1974).

\section{Infusion of drugs (Fig. 2)}

L-noradrenaline was infused at progressively increasing rates of $2,4,6$, and $8 \mu \mathrm{g} / \mathrm{min}$, each level being maintained for one minute. At the highest infusion rate, the blood pressure rose to $200 / 100 \mathrm{mmHg}$, and the heart rate decreased to 40 beats $/ \mathrm{min}$. Similar 

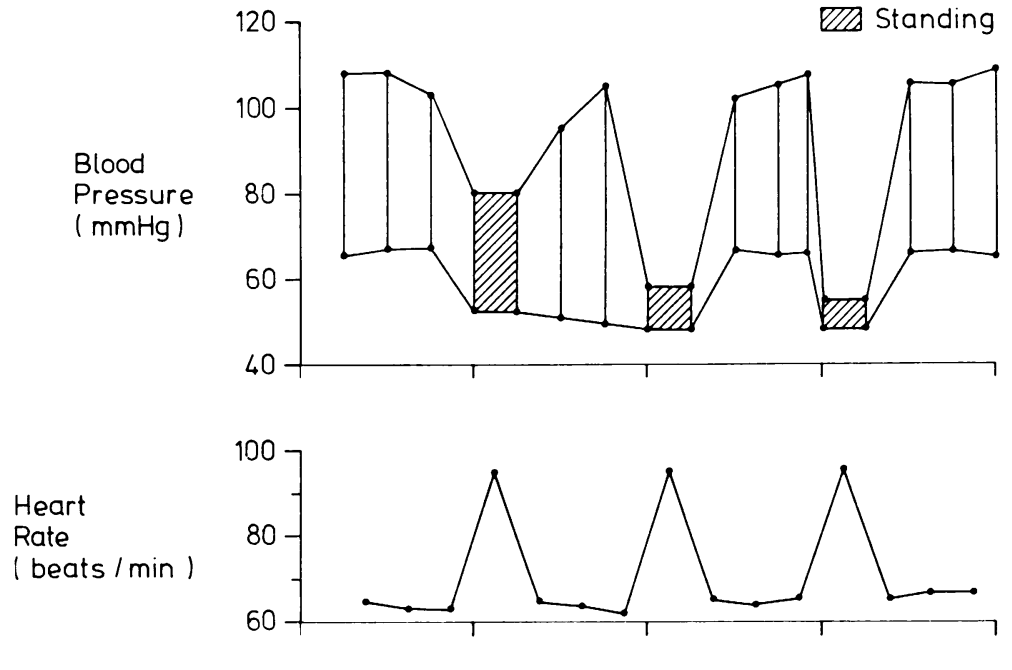

Fig. 1 Response to repeated

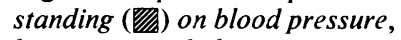
heart rate, and plasma catecholamines $(\times-\times$

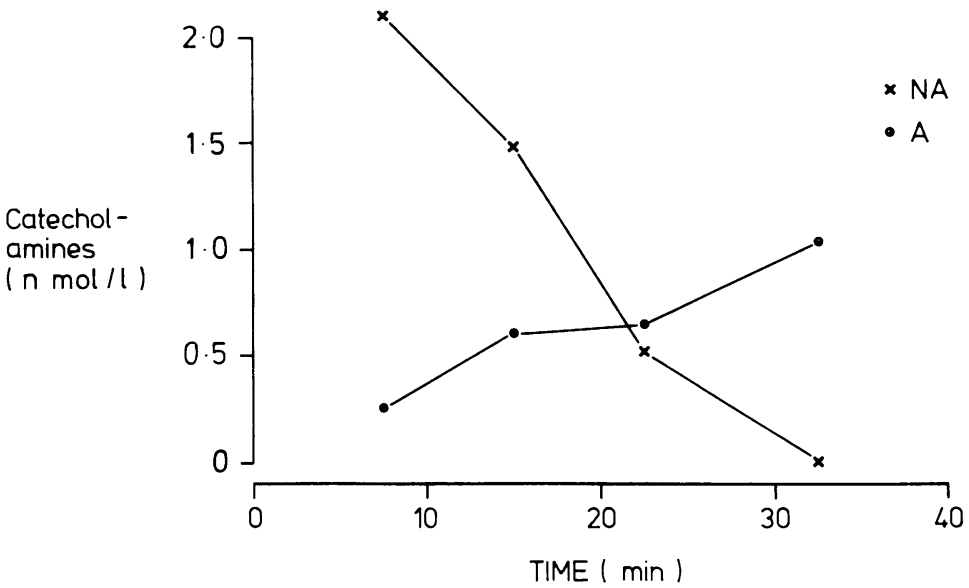
noradrenaline, adrenaline).

results were obtained with infusion of phenylephrine at measured rates of between 60 and $200 \mu \mathrm{g} / \mathrm{min}$. Tyramine infusion at measured rates of $0.5 \mathrm{mg}-$ $20 \mathrm{mg} / \mathrm{min}$ produced no appreciable blood pressure response or change in heart rate. The tyramine infusion was repeated after he had received tranylcypromine (Parnate, Smith Kline and French Laboratories), a monoamine oxidase inhibitor (10 $\mathrm{mg}$ three times daily), for 14 days, and still no increase in blood pressure or change in heart rate was obtained.

\section{Baroreceptor reflex sensitivity}

The sensitivity of the baroreceptor reflex was studied when the patient was supine by injecting phenylephrine (50-150 $\mu \mathrm{g}$ intravenously) as one dose (method of Pickering et al., 1968). The sensitivity of the baroreceptor reflex is assessed as the change in heart rate with unit change of blood pressure, and expressed as the slope of the graph relating the pulse interval to systolic arterial blood pressure. This was normal in the patient $(5.8 \mathrm{~ms} / \mathrm{mmHg}$, normal range 2.8 $12.0 \mathrm{~ms} / \mathrm{mmHg}$ ).

\section{Gastric acidity}

The gastric response to a standard insulin test of 0.2 units $/ \mathrm{kg}$ body weight of soluble insulin subcutaneously (Bachrach, 1953) produced an increase in acid concentration from a maximal basal value of $36 \mathrm{mmol} / 1$ to $66 \mathrm{mmol} / 1$ in 60 minutes. An increase of more than $20 \mathrm{mmol} / 1$ in acid concentration over the maximum basal value suggests intact vagal activity.

\section{Sweating in response to heat}

The ability to sweat in response to heat was tested by exposing the patient for $\mathbf{3 0}$ minutes to a radiant heat 


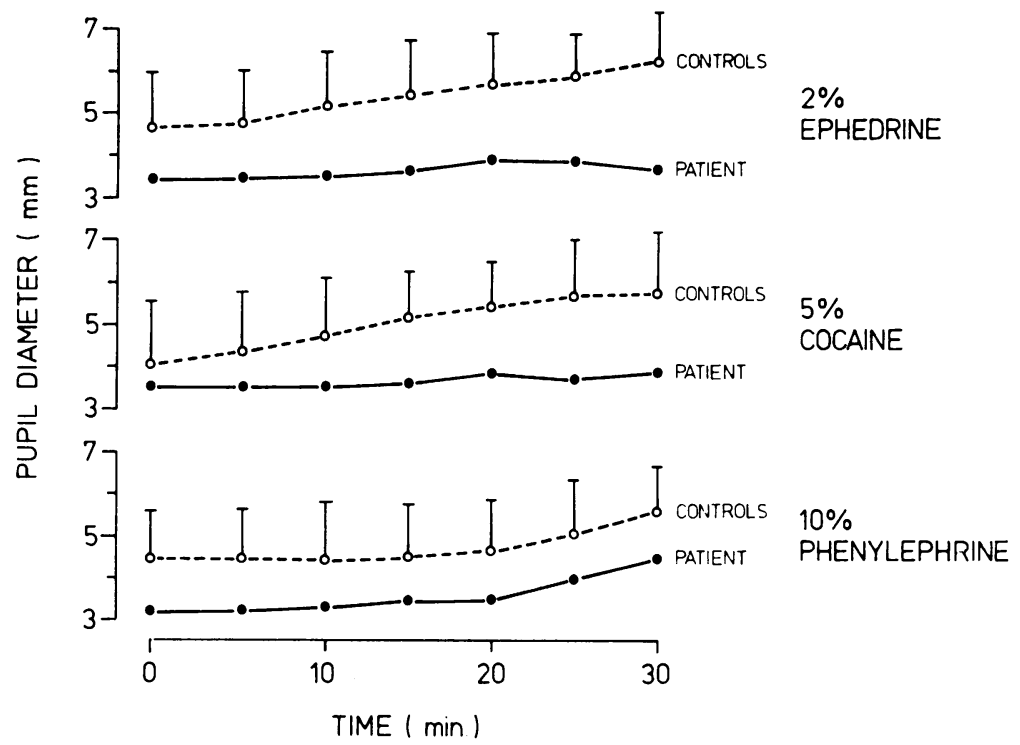

Fig. 2 Mydriatic response of patient's pupils $(\mathbf{O}-\mathbf{O})$ to ephedrine $(2 \%)$, cocaine $(5 \%)$, and phenylephrine $(10 \%)$ compared with four controls $(\bigcirc---\bigcirc)$ matched for age and iris colour. The error bars represent the standard deviation of mydriasis in controls.

cradle over the trunk while he lay on an electric blanket. The presence and the anatomical distribution of sweating was demonstrated by the application of 1,4-dihydroxyanthraquinone-starch powder as an indicator (Guttmann, 1940). The patient sweated normally except in the axillae and groins. In these regions, apocrine glands are most numerous, and these normally respond to circulating humoral agents, chiefly adrenaline.

\section{Iontophoresis of acetylcholine}

Freshly prepared O-acetylcholine perchlorate solution $(10 \%)$ was iontophoresed (Macmillan and Spalding, 1969) at several sites on the trunk, arms, and legs, and produced sweating and piloerection in areas of 1-2 cm diameter.

\section{Investigations of pupillary responses}

The nature and extent of autonomic control of the iris musculature was tested using a photographic method (Sneddon and Turner, 1967). Each test was carried out with at least a three day interval from other ocular tests. To test for the presence of an intact and functional parasympathetic innervation of the pupillary musculature, one drop of physostigmine $(0.5 \%)$ was applied to the left conjunctival sac, and produced the same degree of miosis in the patient as in control subjects. Two drops of methacholine $(2.5 \%)$ were instilled into the conjunctival sacs without any response. The sympathetic neural control of the pupillary musculature was examined by studying the reactions to darkness and to three drugs (Fig. 3); phenylephrine, which directly stimulates the a receptors on the smooth muscle; ephedrine, whose action is mainly due to the release of noradrenaline from the sympathetic nerve endings; and cocaine, which potentiates normal sympathetic neural tone by preventing the re-uptake of the released noradrenaline. The effects were compared with the findings in four normal subjects matched for age and iris colour. During a 30 minute period in the dark the patient's pupils dilated to $4.3 \mathrm{~mm}$ compared with a mean of $6.4 \mathrm{~mm}$ in four control subjects (range 5.9-6.8 mm). All three drugs caused mydriasis in the control subjects. Phenylephrine caused mydriasis in the patient which was proportionately equal to that in the controls. Neither ephedrine nor cocaine produced a significant effect in the patient.

\section{Thermal response to electrical stimulation of the sural nerve}

A surface electrode was used to stimulate the sural nerve $5 \mathrm{~cm}$ proximal to the lateral maleolus. The nerve was stimulated at a frequency of one impulse per second for 60 seconds. Current intensity and pulse duration were $20 \mathrm{~mA}$ and $0.2 \mathrm{~ms}$ respectively. In normal subjects, the procedure causes a reversible fall in temperature of about $1^{\circ} \mathrm{C}$ over the skin surface supplied by the dorsalis pedis artery, with no change over the foot of the contralateral leg. In the patient, it was not possible to lower the temperature over the foot during sural nerve stimulation.

\section{Cerebrospinal fuid studies}

Cerebrospinal fluid was analysed for homovanillic acid (HVA) and 5-hydroxyindoleacetic acid (5-HIAA) 


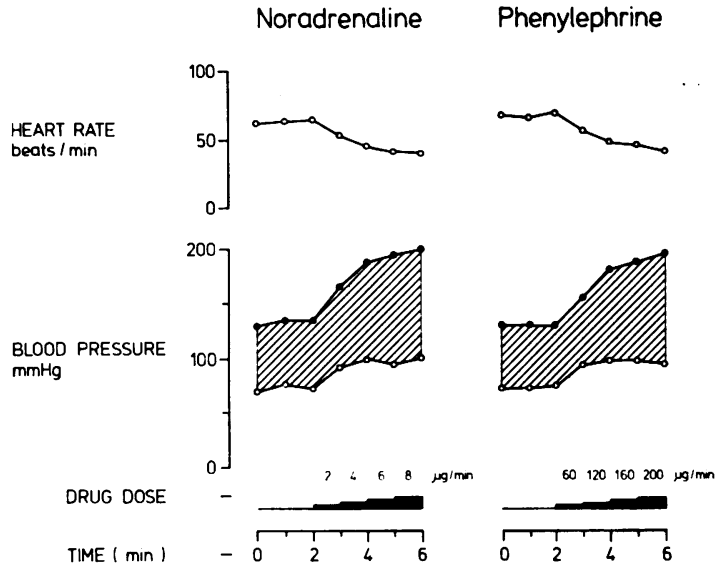

(method of Ashcroft et al., 1968). HVA was abnormally low $(0.08 \mu \mathrm{mol} / 1$; normal range $0.22-0.44 \mu \mathrm{mol} / 1)$, HIAA was normal $(0.11 \mu \mathrm{mol} / \mathrm{l}$, normal range $0.08-0.13 \mu \mathrm{mol} / \mathrm{l})$. Cerebrospinal fluid was examined again after the patient had been on levodopa therapy for 14 days. The concentration of HVA was 0.65 $\mu \mathrm{mol} / 1$, and that of HIAA was $0.11 \mu \mathrm{mol} / 1$.

\section{Investigations of patient's impotence}

The following investigations were carried out: plasma testosterone ( $18.68 \mathrm{nmol} / 1$; normal); seminal smears for sperm count (repeated ón three occasions, no spermatozoa identified); intravenous pyelogram (normal); cystoscopic examination (a wide bladder neck was seen with early fine trabeculation of the bladder, and the internal sphincter appeared to be inactive); microscopic examination of urine for spermatozoa after orgasm revealed normal spermatozoa, indicating retrograde ejaculation.

\section{MUSCLE BIOPSIES}

Biopsies were taken from the left palmaris longus and the right vastus medialis muscles under local anaesthesia. The tissues were prepared for fluorescence microscopy. Specimens of muscle were frozen in isopentane, cooled in liquid nitrogen, dried in a Pearse Speedivac freeze drier for 18 hours, and then exposed to paraformaldehyde vapour at $80^{\circ} \mathrm{C}$ for one hour. The tissue blocks were embedded in vacuo in wax, and $6 \mu \mathrm{m}$ sections cut and mounted in liquid paraffin. Sections were examined in either a Leitz fluorescence Ortholux microscope or in a Leitz microspectrograph (MSG). In the Ortholux microscope, dark field illumination was used, with a mercury vapour lamp ( $\mathrm{HgO} 200)$ as light source. The appropriate exciting wavelengths were isolated by a $3 \mathrm{~mm}$ BG12 excitor filter and a Leitz $530 \mathrm{~nm}$ barrier filter was placed above the objective. The sections
Tyramine

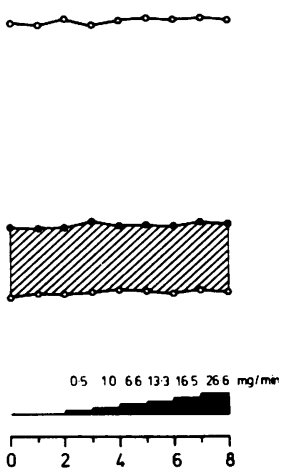

Fig. 3 Blood pressure and heart rate with infusions of noradrenaline, phenylephrine, and tyramine. were photographed using an Orthomat camera attached to the microscope. In the Leitz MSG, incident illumination with Ploem dichroic mirrors was used, with a Xe 150 lamp as light source. The excitation wavelength was isolated by a $435 \mathrm{~nm}$ narrow band filter. The fluorescence light emitted by the specimen passed first through a prism, and the dispersed light was then deflected into the entry slit of a photomultiplier tube by an oscillating mirror. The output from the photomultiplier tube was applied to the $\mathrm{Y}$-axis of an $\mathrm{XY}$ recorder, with the $\mathrm{X}$-axis driven by voltage from a potentiometer attached to the oscillating mirror which was calibrated against wavelength. An oil immersion objective $(\times 54)$ was used so that the emission spectrum of the light from a small selected area of $1.0 \mu \mathrm{m}^{2}$ of the specimen was obtained. It was possible, therefore, to identify substances present in the tissue, and to distinguish between substances with subjectively similar fluorescence characteristics.

Blood vessels in both the palmaris longus and vastus medialis were observed to be supplied with structures at their adventitio-medial junction which were anatomically similar to normal adrenergic nerve fibres (Fig. 4). These showed the same intense apple green fluorescence characteristic of noradrenaline. The identification of the fluorophor in the nerve fibres as noradrenaline, and its distinction from collagen, was made by recording the fluorescence emission spectrum and comparing it with adjacent collagen fibres. Lipofuchsin, which was also present in these smooth muscle cells, was also examined. The spectra corrected for light absorption are illustrated in Fig. 5. Included in Fig. 5 is the spectrum recorded from adrenergic nerves from other specimens. From the coincidence of the spectra from adrenergic fibres and the suspected adrenergic fibres in the muscle, and their distinction from the spectra for collagen and 


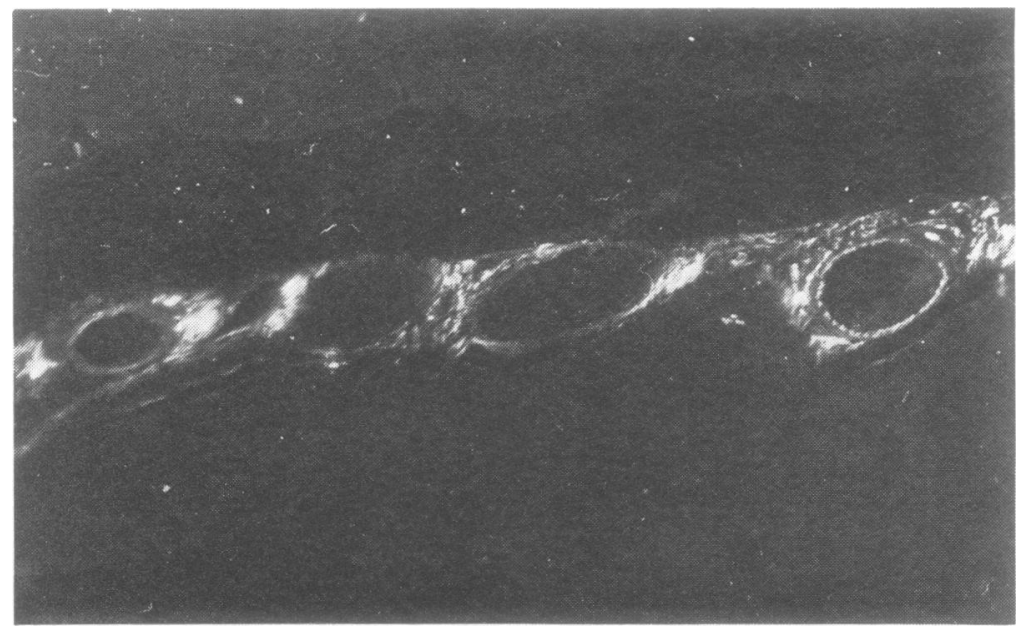

Fig. 4 Fluorescence micrograph of vastus medialis muscle. Adrenergic nerve terminals can be seen on the adventitial surface of the blood vessels.

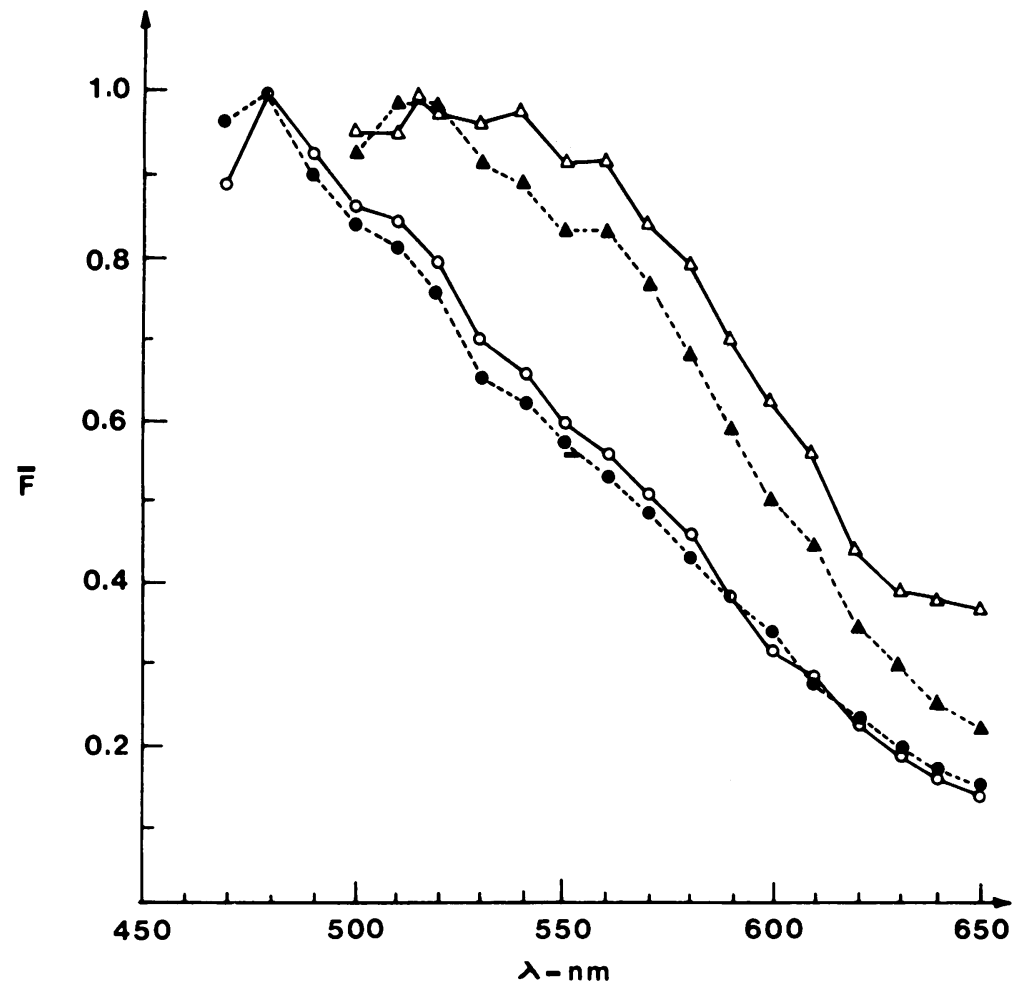

Fig. 5 Fluorescence emission spectra from patient's adrenergic nerves $(\bigcirc-\bigcirc)$, collagen $(\mathbf{\Delta}---\mathbf{\Delta})$, and skeletal muscle $(\triangle-\triangle)$, compared with the fluorescence of adrenergic nerves from animal material $\left(\bullet_{---\bullet}\right)$.

lipofuchsin, it was concluded that the blood vessels supplying limb skeletal muscles were innervated by postganglionic sympathetic adrenergic nerve fibres. The intensity of fluorescence was also within the normal range for known adrenergic nerves innervating blood vessels, suggesting that the total stores of noradrenaline in this patient's nerves were within normal limits.

\section{Treatment}

The patient had been treated for many years with anticonvulsant drugs as his frequent episodes of loss of consciousness had been interpreted as epileptic in nature. Previous unsuccessful treatment for orthostatic hypotension had included ephedrine, 9- $\alpha$ fluorohydrocortisone, elastic stockings and abdomi- 
nal support, and also an anti- $g$ suit. Treatment using a combination of monoamine oxidase inhibition and tyramine, successful in other patients with neurogenic orthostatic hypotension (Nanda et al., 1975), produced no pressor response in this patient. In view of the normal responses of blood pressure and pupils to phenylephrine during our investigations, it was decided to treat him with this drug. Phenylephrine powder (50 mg, Boots Pharmaceutical Co.), was given orally packed in capsules. The patient's orthostatic hypotension responded well to this drug, and he was able to walk or stand without symptoms throughout the day, with a dose of one capsule given five times daily. He has been on this treatment for six months, and has been able to return to his previous occupation.

\section{Discussion}

Orthostatic hypotension is a common presenting symptom of autonomic failure, and this may have a number of causes. In some patients, autonomic failure may occur with no other evidence of neurological disease, 'idiopathic orthostatic hypotension', and in others it is accompanied by multiple system degeneration elsewhere in the nervous systemnotably olivopontocerebellar atrophy and similar syndromes-and also Parkinsonism (for reviews see Johnson and Spalding, 1974, 1976). The sympathetic failure in both groups of patients normally develops in late middle life, and is related to degeneration of cells in the intermediolateral columns of the spinal cord (Johnson et al., 1966). Autonomic degeneration may occur in children with familial dysautonomia (Riley-Day syndrome, Riley 1957), although the disease may occasionally appear spontaneously. In this disorder, however, there is eventually widespread clinical involvement of the nervous system. Both in idiopathic orthostatic hypotension and familial dysautonomia, degeneration of the autonomic nervous system is a chronic progressive disorder. Pure pan-dysautonomia of acute onset has also been described (Young et al., 1969; Hopkins et al., 1974; Young et al., 1975) with involvement of both sympathetic and parasympathetic fibres. The majority of patients recover over a period of months (Okada et al., 1975), but recovery may take years. In such cases degeneration of peripheral autonomic fibres has been demonstrated (Appenzeller and Kornfeld, 1973).

The patient we have described had orthostatic hypotension with several unusual features including early age of onset, long duration of symptoms, lack of progression, and no evidence of involvement of cholinergic sympathetic or parasympathetic pathways. Blood pressure studies confirmed the orthostatic hypotension, and no evidence of vaso- constriction was present during or after Valsalva's manoeuvre, indicating interruption of circulatory reflexes. The absence of a rise in blood pressure after a sudden noise or with mental arithmetic suggested that the defect was in the central or efferent nerve fibres subserving vasomotor function (SharpeySchafer, 1956; Sharpey-Schafer and Taylor, 1960). However, an increase of heart rate with change of posture and in response to atropine and deep breathing, suggested that the patient had normal vagal innervation of the heart (Wheeler and Watkins, 1973). The absence of a further increase in heart rate during orthostatic hypotension after atropine suggested that the defect of sympathetic activity also affects the heart. Vagal innervation of the stomach was also active as indicated by the production of normal amounts of gastric acid during a standard insulin test meal. These tests indicated normal efferent parasympathetic function (cholinergic). Normal sweating in response to heat demonstrated the presence of normal sympathetic cholinergic mechanisms. A surrounding area of skin developed sweating and piloerection with local iontophoresis of acetylcholine. Action on surrounding sweat glands and piloerector muscles requires intact axon reflexes in postganglionic cholinergic sympathetic fibres (Bárány and Cooper, 1956), which were therefore present in this patient. During repeated tilting from the horizontal to the vertical, there was a fall of circulating noradrenaline, while adrenaline levels rose. These results may indicate a defect in the release of noradrenaline from the peripheral vasomotor nerves in response to repeated changes in posture. Noradrenaline comes predominantly from these nerves, release being related to calcium ions. In our patient, therefore, the source of the noradrenaline in the resting state is not clear, although it is possible that resting catecholamines were derived from the adrenal glands rather than vasomotor nerves. The absence of a vascular response during electrical stimulation of the sural nerve is another indication of the failure of nerve stimulation to release vasoconstrictor substances. Treatment with tyramine, an indirect sympathomimetic agent which acts by displacing noradrenaline from sympathetic vesicles, failed to raise the blood pressure (Nanda et al., 1975). This is further evidence of a defect in the release of noradrenaline and as this action does not require calcium ions, it would appear that the defect is not dependent upon abnormalities affecting calcium ions at sympathetic nerve endings (Lindmar et al., 1967; Kirpekar et al., 1972). Lack of vasoconstriction in response to tyramine has been reported in four patients with idiopathic orthostatic hypotension in whom sympathetic vasomotor nerves were shown to have no catecholamine-specific fluorescence (Kontos et al., 1975). In our patient, however, the peripheral 
blood vessels were innervated with adrenergic nerves. The failure of the patient to respond to therapy with tyramine and a monoamine oxidase inhibitor suggests that he had a failure of noradrenaline release, even though sympathetic fibres were present. His response to therapy with phenylephrine indicates that his blood vessels are able to constrict to sympathetic receptor stimulation. This is further evidence for the lesion being specific to the sympathetic terminals.

The response of the patient's pupils to physostigmine suggests that parasympathetic innervation and tone were present. The similar resting pupil diameter in the patient compared with those observed in control subjects, and his smaller increase in pupil diameter in the dark, also supported the conclusion that parasympathetic tone was present. The dilator response to phenylephrine, a direct sympathomimetic drug acting on adrenoreceptors suggested that the dilator pupillae muscle, which is adrenergic, was normal. The minimal effect of cocaine suggested the absence of effective sympathetic neural tone (Jaffe, 1950), since this drug acts by potentiating noradrenaline released from sympathetic nerves by preventing its re-uptake (Hertting et al., 1961; Muscholl, 1961). The lack of effect of ephedrine, also an indirect sympathomimetic, supports our conclusion that this patient had failure of noradrenaline release.

The results of the investigations of the patient's impotence were consistent with deficient activity of the internal urethral sphincter at the bladder neck. This is normally innervated by adrenergic sympathetic nerves. The demonstration of spermatozoa in the patient's urine confirmed that the patient had retrograde ejaculation as would occur with this defect (see Johnson and Spalding, 1974). The cerebrospinal fluid studies are difficult to explain. The initial low HVA level would be consistent with failure of the enzymes involved in dopamine metabolism, but these were shown to be active when levodopa was given.

We conclude that our patient's orthostatic hypotension was due to failure of noradrenaline release. This was absent even though sympathetic nerves supplying peripheral blood vessels were present.

We wish to thank the patient for his cooperation, and the Scottish Hospital Endowments Research Trust, Secretary of State for Scotland, and Roche Products Ltd. for financial support.

\section{References}

Appenzeller, O., and Kornfeld, M. (1973). Acute pandysautonomia: clinical and morphologic study. Archives of Neurology (Chic.), 29, 334-339.

Ashcroft, G. W., Crawford, T. B. B., Dow, R. C., and
Goldberg, H. C. (1968). Homovanillic acid, 3,4dihydroxyphenylacetic acid and 5-hydroxyindol-3ylacetic acid in serial samples of cerebrospinal fluid from the lateral ventricle of the dog. British Journal of Pharmacology, 33, 441-456.

Bachrach, W. H. (1953). Action of insulin hypoglycaemia on motor and secretory functions of the digestive tract. Physiology Reviews, 33, 566-592.

Bárány, F. R., and Cooper, E. H. (1956). Pilomotor and sudomotor innervation in diabetes. Clinical Science, 15, 533-540.

Barnett, A. J., Hamilton, M. D., and Kay, H. B. (1955). Severe orthostatic hypotension. Australasian Annals of Medicine, 4, 183-194.

Guttmann, L. (1940). Disturbances of sweat secretion after complete lesions of peripheral nerves. Journal of Neurology and Psychiatry, 3, 197-210.

Hertting, G., Axelrod, J., and Whitby, L. G. (1961). Effect of drugs on the uptake and metabolism of $\mathrm{H}^{3}$-norepinephrine. Journal of Pharmacology and Experimental Therapeutics, 134, 146-153.

Hickler, R. B., Thomson, G. R., and Fox, L. M. (1959). Successful treatment of orthostatic hypotension with 9-alpha-fluorohydrocortisone. New England Journal of Medicine, 261, 788-791.

Hopkins, A., Neville, B., and Bannister, R. G. (1974). Autonomic neuropathy of acute onset. Lancet, 10 $\vec{A}$ 769-771.

Jaffe, N. S. (1950). Localization of lesions causing Horner's syndrome. Archives of Ophthalmology, 44, 710-728.

Johnson, R. H., Lee, G. de J., Oppenheimer, D. R., and Spalding, J. M. K. (1966). Autonomic failure with orthostatic hypotension due to intermediolaterato column degeneration. Quarterly Journal of Medicine 35, 276-292.

Johnson, R. H., and Spalding, J. M. K. (1974). Disorders of the Autonomic Nervous System. Blackwell: Oxford.

Johnson, R. H., and Spalding, J. M. K. (1976). Widespread autonomic failure: effects on body temperature and blood pressure regulation. British Journal of Hospital Medicine, 15, 266-274.

Kirpekar, S. M., Prat, J. C., Puig, Margarita, and Wakade, A. R. (1972). Modification of the evoked release of noradrenaline from the perfused cat spleen by various ions and agents. Journal of Physiology, 221, 601-615.

Kontos, H. A., Richardson, D. W., and Norvell, J. E (1975). Norepinephrine depletion in idiopathic orthostatic hypotension. Annals of Internal Medicine, 82, 336-341.

Lindmar, R., Lösselholz, K., and Muscholl, E. (1967). Untershiede Zwischen Tyramin und Dimethylphenylpiperzin in der $\mathrm{Ca}^{++}$Abhängigkeit und im Zeitlichen Verlauf der Noradrenalin-Freisetzung am Isolierten Kaninchenherzen. Experientia, 23, 933-934.

Luft, R., and Von Euler, U.S. (1953). Two cases of postural hypotension showing a deficiency in release of norepinephrine and epinephrine. Journal of Clinical Investigation, 32, 1065-1069.

Macmillan, A. L., and Spalding, J. M. K. (1969). Human sweating response to electrophoresed acetylcholine: a test of postganglionic sympathetic function. Journal of Neurology, Ncurosurgery, and Psychiatry, 32, 155-160. 
Muscholl, E. (1961). Effect of cocaine and related drugs on the uptake of noradrenaline by heart and spleen. British Journal of Pharmacology, 16, 352-359.

Nanda, R. N., Johnson, R. H., and Keogh, H. J. (1976). Treatment of neurogenic orthostatic hypotension with monoamine oxidase inhibition and tyramine. Lancet, 2, 1164-1167.

Okada, F., Yamashita, I., and Suwa, N. (1975). Two cases of acute pan-dysautonomia. Archives of Neurology (Chic.), 32, 146-151.

Pickering, G. W., Sleight, P., and Smyth, H. S. (1968). The reflex regulation of arterial pressure during sleep in man. Journal of Physiology, 194, 46-48P.

Rennie, M. J. (1974). Physiological and Biochemical Changes with Exercise. PhD Thesis: University of Glasgow.

Riley, C. M. (1957). Familial dysautonomia. Advances in Pediatrics, 9, 157-190.

Sharpey-Schafer, E. P. (1956). Circulatory reflexes in chronic disease of the afferent nervous system. Journal of Physiology, 134, 1-10.
Sharpey-Schafer, E. P., and Taylor, P. J. (1960). Absent circulatory reflexes in diabetic neuritis. Lancet, 1, 559-562.

Sneddon, J. M., and Turner, P. (1967). The effect of local guanethidine on the palpebral fissure and the pupil in thyrotoxicosis, and its inter-action with sympathomimetic amines. Journal of Physiology, 189, 20-22P.

Valori, C., Brunori, C. A., Renzini, V., and Corea, L. (1970). Improved procedure for formation of epinephrine and norepinephrine fluorophors by the trihydroxyindole reaction. Analytical Biochemistry, 33, 158-167.

Wheeler, T., and Watkins, P. J. (1973). Cardiac denervation in diabetes. British Medical Journal, 4, 584-586.

Young, R. R., Ashbury, A. K., Adams, R. D., and Corbett, J. L. (1969). Pure pan-dysautonomia with recovery. Transactions of the American Neurological Association, 94, 355-357.

Young, R. R., Ashbury, A. K., Corbett, J. L., and Adams, R. D. (1975). Pure pan-dysautonomia with recovery. Brain, 98, 613-636. 